\title{
Geologia e geoquímica da soleira de Reserva, estado do Paraná
}

\author{
Eliane Petersohn ${ }^{1}$ \& Eleonora Maria Gouvea ${ }^{2}$
}

\begin{abstract}
Resumo Estudos realizados na soleira de Reserva, um dos mais expressivos corpos básicos intrusivos do Estado do Paraná, permitem fornecer uma visão geral do seu arcabouço geológico e geoquímico, voltada para a elaboração de modelos de evolução magmática e a relação com suas rochas encaixantes. A soleira é formada por basalto, microgabro e gabro, marcados por forte variação textural decorrente do mecanismo de diferenciação magmática. Outras feições de campo incluem metamorfismo e auréolas de contato e zonas de rápido resfriamento. As rochas são formadas por labradorita, augita, magnetita, ilmenite e quartzo, tendo como acessórios titanita, apatita e pirita. As rochas encaixantes, classificadas como argilitos, siltitos e arenitos, compõemse predominantemente por quartzo (60 a 75\%), além de feldspato, epidoto, biotita, muscovita, argilominerais e minerais opacos. Análises por difratometria de raios X nestas rochas revelam quartzo como fase principal, além de albita, sanidina e argilominerais (vermiculita, ilita e muscovita). Dados geoquímicos de elementos maiores e traços permitem classificar as rochas da soleira de Reserva como basaltos andesíticos, lati-andesitos e andesitos, além de basaltos toleíticos, lati-basaltos e um quartzo-latito. Estas rochas apresentam elevadas concentrações de $\mathrm{TiO}_{2}(>2 \%)$ e são classificadas como sendo dos tipos Pitanga e Paranapanema. Diagramas de variação apontam a cristalização fracionada como importante mecanismo na evolução e gênese destas rochas. Modelos de distribuição considerando ID, \#mg, $\mathrm{Ca} /(\mathrm{Ca}+\mathrm{Na})$ e álcalis definem a presença de uma faixa menos diferenciada na porção leste do corpo, sugerindo que a evolução magmática se processou de leste para oeste.
\end{abstract}

Palavras-chave: Soleira de Reserva, geoquímica, modelos de distribuição.

\begin{abstract}
Geology and geochemistry of the Reserva sill, Paraná state. Studies carried on the Reserva Sill, one of the most important intrusive basic bodies of the Paraná State, reveal the general geologic and geochemistry framework, toward to the elaboration of magmatic evolution models and the relation with hosted rocks. The Reserva Sill is formed by basalt, microgabbro and gabbro, marked by strong textural variation due to magmatic differentiation mechanism. Other field features include metamorphism, contact aureoles and fast cooling zones. The rocks are composed by labradorite, augite, magnetite, ilmenita and quartz and accessory minerals: titanite, apatite and pyrite. The host rocks are classified as shale, siltstone and sandstone and composed predominantly by quartz, feldspar, epidote, biotite, muscovite, clay and opaque minerals. X-ray difratometry analisys in sedimentary rocks reveal quartz as main phase. In addiction occur albite, ilite, vermiculite, sanidine, muscovite and clay minerals. Geochemistry data of major and trace elements in igneous rocks allow to classify Reserva Sill rocks as andesi-basalt, lati-andesite and andesite; tholeiit basalt, lati-basalt and quartz-latite. These rocks show high concentrations of $\mathrm{TiO}_{2}(>2 \%)$ and are classified as Pitanga and Paranapanema types. Variation diagrams reveal the fractional crystallization as important mechanism in the genetic evolution of these rocks. Distribution models built (differentiation index, $\# \mathrm{mg}, \mathrm{Ca} /(\mathrm{Ca}+\mathrm{Na})$ indicate the presence of a less differentiated part in the eastern portion of the intrusive body, suggesting that the magmatic evolution occurred from east to west.
\end{abstract}

Keywords: Reserva Sill, geochemistry, distribution models.

INTRODUÇÃ̃ A soleira de Reserva, uma das mais expressivas soleiras do Estado do Paraná, aflora na região centro-leste do estado. Localiza-se no município de Reserva e é delimitada pelas coordenadas 7.288 .718 e $7.267 .922 \mathrm{~m} \mathrm{~N}$ e 509.014 e $525.506 \mathrm{~m} \mathrm{E}$, perfazendo aproximadamente $40 \mathrm{~km}^{2}$ de área aflorante (Fig. 1).

O corpo intrusivo está associado ao falhamento e grande lineamento magnético designado Rio Alonzo (Ferreira et al. 1982), ao qual se associam também diferenciados ácidos vulcânicos. Ocorre encaixado nas rochas sedimentares da Bacia do Paraná, representados, na porção basal, por siltitos arenosos da Formação Palermo e, a leste e oeste, por folhelhos e argilitos da Formação Irati. Nas adjacências, afloram ainda sedimentos das formações Teresina e Rio Bonito e do Grupo Itararé.

Uma visão geral do arcabouço geológico e geoquímico da soleira, voltada para a elaboração de modelos de evolução magmática e a relação com suas rochas encaixantes, constitui o principal objetivo deste trabalho. Para tanto, são utilizados dados pré-existentes acrescidos de novas observações de campo, dados de petrografia e litoquímica integrados para a construção dos modelos de evolutivos. 

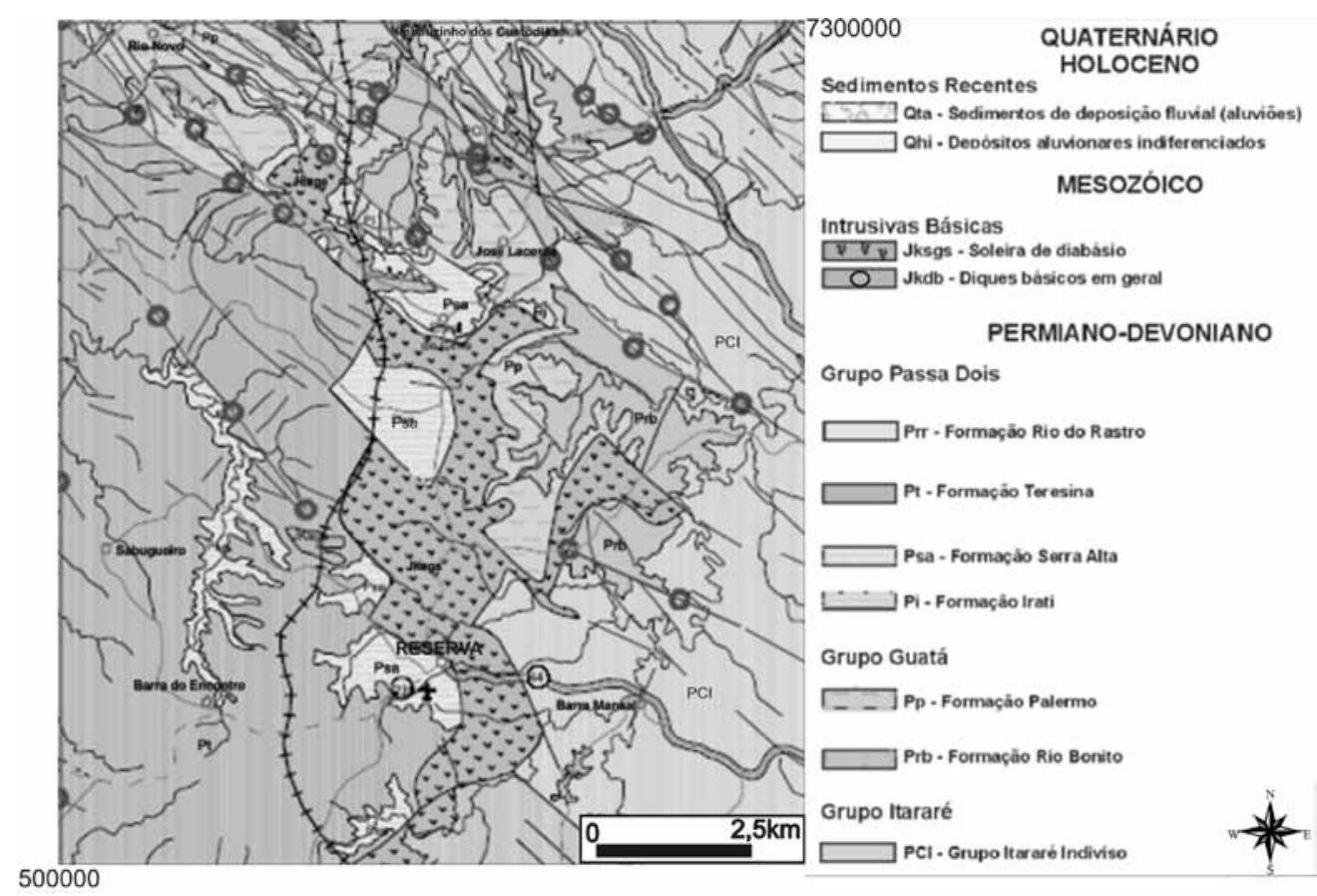

Figura 1 - Mapa geológico da região da soleira de Reserva (extraído de MINEROPAR 2001).

CONTEXTo GeOlógico A Bacia do Paraná é marcada pela maior manifestação de vulcanismo fissural ocorrida em região continental, decorrente dos estágios precoces da ruptura do Gondwana e da abertura do Atlântico Sul, que resultou no empilhamento de até $2.000 \mathrm{~m}$ de basaltos sobre as rochas sedimentares da bacia, além de intrudir-se por entre os mesmos, sob a forma de diques e soleiras (Fodor et al. 1985; Milani e Thomaz Filho 2000). As rochas extrusivas e intrusivas que ocorrem na Bacia do Paraná constituem a Província Magmática do Paraná (PMP).

As rochas vulcânicas, especialmente aquelas pertencentes aos derrames, foram extensivamente estudadas. Estudos geoquímicos importantes foram desenvolvidos por Bellieni et al. (1983, 1984a, 1984b, 1986), Mantovani et al. (1985), Piccirillo et al. (1987, 1988), Piccirillo \& Melfi (1988), Peate et al. (1990, 1996), Peate (1997), entre outros. Estes estudos mostram que os basaltos e andesi-basaltos toléticos podem ser agrupados em dois grandes conjuntos, que se distinguem pelos teores de titânio. $\mathrm{O}$ grupo contendo $\mathrm{TiO}_{2}<2 \%$ (BTi) caracteriza-se pelo empobrecimento em $\mathrm{P}, \mathrm{Sr}, \mathrm{Ba}, \mathrm{La}, \mathrm{Ce}, \mathrm{Zr}$ e $\mathrm{Y}$, em relação às rochas básicas com $\mathrm{TiO}_{2}>2 \%$ (ATi), caracterizada por concentrações relativamente altas de $\mathrm{P}$, de elementos traços incompatíveis ( $\mathrm{Sr}, \mathrm{Zr}, \mathrm{Hf}, \mathrm{Ba}, \mathrm{Ta}, \mathrm{Y}$ ) e terras raras leves. As rochas básicas BTi ocorrem preferencialmente na subprovíncia sul da PMP, enquanto que o grupo ATi predomina na subprovíncia norte (Marques \& Ernesto 2004). Peate et al. (1990, 1996) e Peate (1997) distinguem seis tipos magmáticos, agrupados dentro das variedades alto e baixo titânio, e divididos em função das razões de elementos traço e características isotópicas. Dentro do grupo de baixo titânio são definidos os magmas-tipo Gramado, Ribeira e Esmeralda e, no de alto titânio, Urubici, Pitanga e Paranapanema.

A geologia das rochas intrusivas é pouco conhecida, contudo, as soleiras da PMP foram estudadas por: Bellieni et al. 1984b; Piccirilo et al. 1988; Maniesi 1991; Maniesi \& Oliveira 1997; Ernesto et al. 1999; Vasconcellos et al. 2003, 2005; Petersohn 2006. Estes estudos mostram que estas rochas apresentam caráter predominantemente básico, com características geoquímicas similares àquelas das rochas vulcânicas associadas. As soleiras da subprovíncia sul apresentam baixas concentrações de titânio $\left(\mathrm{TiO}_{2}<2 \%\right)$. Aquelas da subprovíncia norte possuem concentrações relativamente elevadas $\left(\mathrm{TiO}_{2}>2 \%\right)$. A variação composicional indica que a cristalização fracionada desempenhou um papel importante na gênese destas rochas.

\section{RELAÇÕES DE CAMPO E CARACTERÍSTICAS} MESOSCÓPICAS A soleira de Reserva é formada predominantemente por rochas básicas, classificadas de acordo com sua granulação em basalto, microgabro e gabro, cinza escuros e maciços, marcados por forte variação textural decorrente do processo de diferenciação magmática. Nos contatos com as rochas encaixantes exibe zonas de resfriamento rápido, incluindo feições amigdaloidais e granulometria crescente para a base. É comum a variação textural de basalto nas bordas para microgabro e gabro nas porções centrais do corpo, indicando acentuada diferenciação textural. Há predomínio de texturas faneríticas inequigranulares médias. Granulação fina e texturas afaníticas predominam no contato com as encaixantes.

As rochas encaixantes são comumente folhelhos e siltitos. Os folhelhos são cinza escuros a esver- 
deados, com granulação fina e composição argilosa e possuem laminação plano-paralela. Os siltitos são de composição síltico-arenosa, castanhos a avermelhados, finos, laminados ou maciços. Ocasionalmente, são descritos calcários cinzas e maciços.

Auréolas de contato são freqüentes na interface soleira - sedimento. Estas auréolas são formadas por rochas coesas, finas, compostas predominantemente por quartzo. A espessura das auréolas é variável, situando-se normalmente entre 10 e $30 \mathrm{~cm}$, podendo se estender por até $1,0 \mathrm{~m}$. Com o aumento da distância do contato verifica-se decréscimo da granulação e redução na proporção de quartzo.

Os afloramentos na região apresentam-se freqüentemente alterados com manto de intemperismo da ordem de 20 a 30 metros de espessura. Entretanto, boas exposições de rocha podem ser encontradas no leito de drenagens, pedreiras desativadas, cachoeiras e no perfil na estrada férrea Apucarana - Paranaguá. Ao longo deste perfil são reconhecidos os contatos superior e inferior da soleira com a encaixante e descritas as principais variações texturais e minerais do corpo.

Estruturas como disjunções colunares são comuns, descritas na região NE da soleira e permitem distingui-la do dique que corta essas rochas. São estruturas tabulares com seções horizontais com formas quadradas, pentagonais e hexagonais com dimensões de até $2,0 \mathrm{~m}$ no eixo maior, dispostas perpendicularmente à superfície do corpo magmático. São decorrentes do processo de contração do magma pela perda progressiva de voláteis durante seu resfriamento.

Outras características descritas em campo incluem sistemas de fraturas, com espaçamento centimétrico a métrico, freqüentemente preenchidas com sulfeto ou carbonato.

PETROGRAFIA As rochas da soleira de Reserva são classificadas com base no diagrama QAPF (Feldspato Alcalino-Plagioclásio-Feldspatóide, Le Maitre 1989) como basaltos. Constituem-se essencialmente por labradorita (Fig. 2A), augita (Fig. 2B), magnetita, ilmenita e quartzo, tendo como acessórios titanita, apatita e pirita. Olivina e feldspato alcalino são raros. Hornblenda, biotita, clorita, argilominerais, carbonato e epidoto ocorrem subordinadamente e são decorrentes do processo de alteração das rochas. As rochas possuem texturas holocristalinas intergranulares, subordinadamente ofíticas e subofíticas e, ainda, subafírica ou porfirítica. As texturas porfiríticas são comuns com fenocristais e microfenocristais de plagioclásio predominantes (Fig.
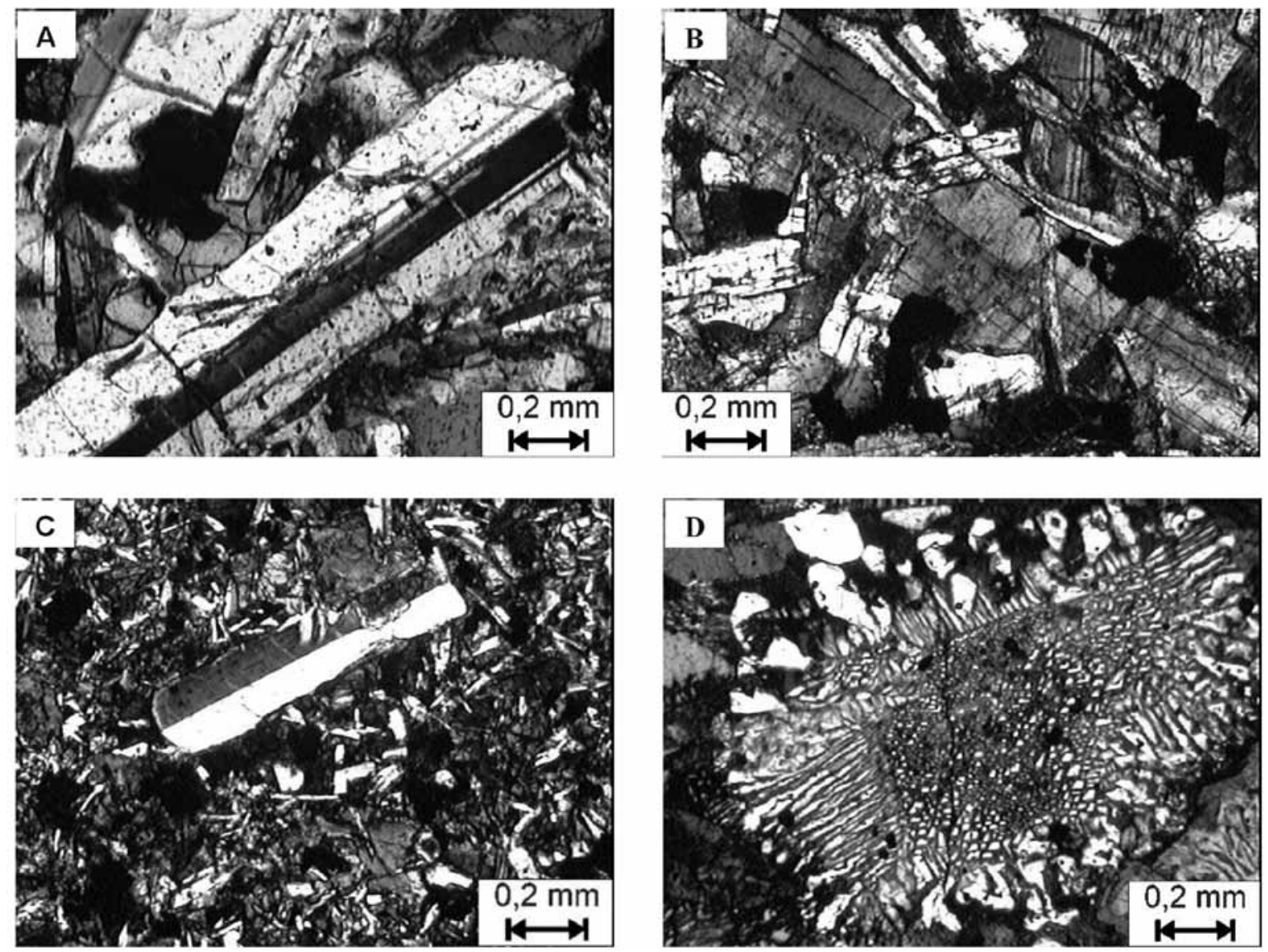

Figura 2 - Fotomicrografias em luz polarizada das rochas estudadas. (A) Fenocristal de plagioclásio em amostra de gabro; (B) Fenocristal de piroxênio em amostra de micrograbro; (C) Basalto com fenocristal de plagioclásio disposto em matriz fina, composta por plagioclásio, piroxênio e minerais opacos e (D) Fenocristal de feldspato alcalino em intercrescimento gráfico com quartzo. 
2C), associados aos microfenocristais de clinopiroxênios e/ ou minerais opacos. A matriz é constituída por plagioclásio, clinopiroxênio e minerais opacos. As fases finais de cristalização magmática são definidas pela ocorrência de quartzo ou vidro vulcânico intersticiais. É comum a presença de quartzo em intercrescimento mirmequítico e gráfico com feldspato alcalino (Fig. 2D). As estruturas destas rochas são predominantemente maciças, ocasionalmente fluidal ou amigadalóide.

As rochas encaixantes são classificadas como siltito, arenito, arenito subarcoseano e folhelho (Fig. 3). Caracterizam-se pelo elevado conteúdo de quartzo (60 a 75\%), além de feldspato, epidoto, biotita, muscovita, argilominerais e minerais opacos. O cimento é silicoso ou carbonático e possuem laminação plano-paralela e textura predominantemente do tipo sustentada pela matriz. As rochas com baixo conteúdo de quartzo compõem-se por argilominerais.

Análises por difratometria de raios $\mathrm{X}$ determinam o quartzo como fase principal, além de albita e sanidina. Vermiculita, ilita e muscovita são os argilominerais mais freqüentes. A presença de calcita também é comum. Em rochas com altas concentrações de calcita ocorrem wollastonita, augita e heulandita. A presença de sanidina em todas as rochas analisadas sugere que o metamorfismo de contato atingiu a fácies sanidinito, condizente com as temperaturas de até $1300^{\circ} \mathrm{C}$ obtidas pela análise dos geotermômetros de plagioclásio e clinopiroxênio (Petersohn, 2006). As análises por difratometria de raios $X$ foram realizadas no Laboratório de Análise de Minerais e Rochas (LAMIR) da Universidade Federal do Paraná. LITOGEOQUÍMICA Da amostragem total realizada na soleira de Reserva, 41 amostras foram analisadas por fluorescência de raios X, para dosagem de elementos maiores e traços (Tab. 1). As análises para elementos maiores foram parcialmente realizadas no laboratório do Instituto de Geociências da Universidade Estadual Paulista, Campus Rio Claro, SP (amostras E da Tab. 1) e parte no Laboratório de Análise de Minerais e Rochas (LAMIR) da Universidade Federal do Paraná (amostras AR da Tab. 1). Todas as amostras foram preparadas no LAMIR, onde foram britadas, moídas e quarteadas.

Em geral as rochas destacam-se pelo conteúdo de $\mathrm{SiO}_{2}$ entre 48,46 a $58,17 \%$, moderados teores de álcalis $(3,0$ a $6,5 \%), \mathrm{TiO}_{2}$ preferencialmente alto $(1,77 \mathrm{a}$ $5,06 \%)$ e $\mathrm{P}_{2} \mathrm{O}_{5}(0,32$ a $1,0 \%)$. $\mathrm{CaO}$ e $\mathrm{MgO}$ variam entre 5,18 a $9,77 \%$ e 1,19 a $8,02 \%$, respectivamente. $\mathrm{FeO}_{\text {tot }}$ varia entre 14,02 a 17,87\%. Cálculos normativos CIPW indicam a presença de quartzo $(<12,30 \%)$ e hiperstênio (até $24,45 \%$ ), valores moderados de magnetita $(4,12$ a $5,26)$ e apatita $(0,74$ a $2,34 \%)$, ausência de olivina e nefelina normativas.

Os dados litoquímicos foram projetados nos diagramas classificatórios TAS e R1R2 (Fig. 4). No diagrama TAS $\left[\left(\mathrm{Na}_{2} \mathrm{O}+\mathrm{K}_{2} \mathrm{O}\right) / \mathrm{SiO}_{2}\right]$ de Le Maitre (1989), as rochas situam-se predominantemente no campo dos basaltos, com quatro amostras de basalto andesítico e uma de traqui-andesito. O diagrama TAS evidencia ainda a presença de rochas básicas e intermediárias. No diagrama R1R2 de De La Roche et al. (1980) o comportamento é semelhante e as rochas são representadas em sua grande maioria por basaltos andesíticos, latiandesitos e andesitos, além de basaltos toléticos, latibasaltos e um quartzo-latito. A disposição dos pontos segue uma tendência com decréscimo de R2 (relação entre $\mathrm{Ca}, \mathrm{Mg}$ e $\mathrm{Al}$ ), indicando o fracionamento dos basaltos toleíticos para o quartzo-latito.

Os diagramas de variação para elementos maiores, tendo o $m g(\mathrm{MgO} /(\mathrm{MgO}+\mathrm{FeO}))$ como índice de diferenciação mostram trends relativamente difusos para a maioria dos óxidos (Fig. 5), com forte dispersão para $\mathrm{FeO}_{\text {tot }}, \mathrm{TiO}_{2}$ e $\mathrm{Al}_{2} \mathrm{O}_{3}$. Os demais óxidos, $\mathrm{SiO}_{2}, \mathrm{Na}_{2} \mathrm{O}$, $\mathrm{K}_{2} \mathrm{O}$ e $\mathrm{P}_{2} \mathrm{O}_{5}$ definem correlações positivas, pouco difusas, com o decréscimo de $m g$, enquanto $\mathrm{CaO}$ define correlação negativa. Embora difusos, os decréscimos observados em $\mathrm{FeO}_{\mathrm{T}}, \mathrm{MgO}$ e $\mathrm{CaO}$ e o enriquecimento
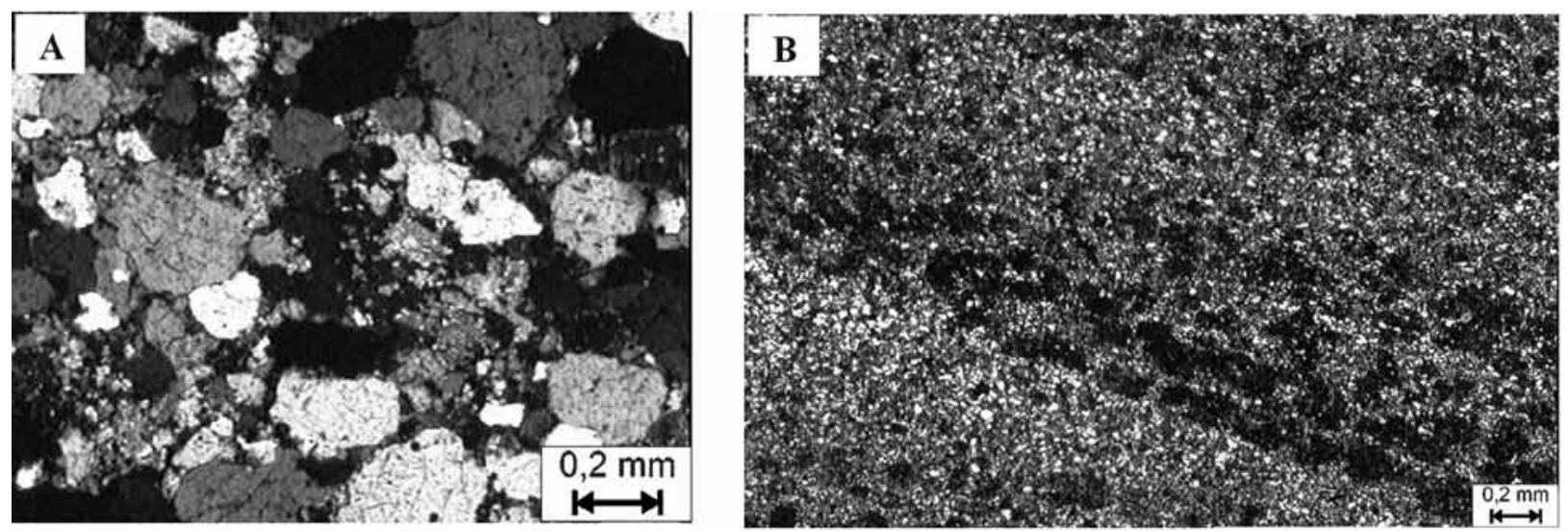

Figura 3 - Fotomicrografias em luz polarizada das rochas encaixantes da soleira de Reserva. (A) Arenito composto por quartzo, plagioclásio, carbonato e biotita, com grãos com contatos flutuantes e cimento carbonático; (B) Arenito subarcoseano composto por quartzo, clorita, biotita e plagioclásio, laminação plano-paralela definida pela intercalação de níveis quartzosos de maior granulação com níveis de granulação subordinada. 
Tabela 1 - Composição química das rochas da soleira de Reserva.

\begin{tabular}{c|c|c|c|c|c|c|c|c|c|c|c|c|c|c|c}
\hline Amostra & $\begin{array}{c}\text { AR- } \\
01 / 01\end{array}$ & $\begin{array}{c}\text { AR- } \\
09 / 17\end{array}$ & $\begin{array}{c}\text { AR- } \\
12 / 19\end{array}$ & $\begin{array}{c}\text { AR- } \\
17 / 40\end{array}$ & $\begin{array}{c}\text { AR- } \\
18 / 41\end{array}$ & $\begin{array}{c}\text { AR- } \\
19 / 43\end{array}$ & $\begin{array}{c}\text { AR- } \\
19 / 44\end{array}$ & $\begin{array}{c}\text { AR- } \\
20 / 45\end{array}$ & $\begin{array}{c}\text { AR- } \\
20 / 46\end{array}$ & $\begin{array}{c}\text { AR- } \\
21 / 47\end{array}$ & $\begin{array}{c}\text { AR- } \\
22 / 48\end{array}$ & $\begin{array}{c}\text { AR- } \\
23 / 50\end{array}$ & $\begin{array}{c}\text { AR- } \\
24 / 51\end{array}$ & $\begin{array}{c}\text { AR- } \\
25 / 52\end{array}$ & $\begin{array}{c}\text { AR- } \\
26 / 53\end{array}$ \\
\hline $\mathrm{SiO}_{2}$ & 52,10 & 49,65 & 51,74 & 50,16 & 54,64 & 50,58 & 48,85 & 51,02 & 50,63 & 50,59 & 51,41 & 50,22 & 50,92 & 49,64 & 50,73 \\
\hline $\mathrm{TiO}_{2}$ & 3,69 & 4,58 & 2,84 & 4,01 & 2,62 & 3,83 & 5,09 & 3,88 & 4,05 & 3,94 & 3,65 & 3,87 & 3,68 & 4,63 & 3,31 \\
\hline $\mathrm{Al}_{2} \mathrm{O}_{3}$ & 12,47 & 12,43 & 14,06 & 12,82 & 11,96 & 13,02 & 12,18 & 12,49 & 12,39 & 12,22 & 12,26 & 12,93 & 12,87 & 11,93 & 14,31 \\
\hline $\mathrm{FeO}_{\text {tot }}$ & 13,07 & 14,00 & 13,77 & 14,31 & 13,80 & 14,04 & 14,89 & 13,71 & 13,69 & 13,73 & 13,85 & 14,29 & 0,20 & 0,21 & 0,18 \\
\hline $\mathrm{MnO}$ & 0,19 & 0,21 & 0,20 & 0,20 & 0,21 & 0,20 & 0,21 & 0,21 & 0,21 & 0,21 & 0,21 & 0,20 & 3,78 & 4,07 & 3,30 \\
\hline $\mathrm{MgO}$ & 3,92 & 3,90 & 3,44 & 3,71 & 2,29 & 3,78 & 4,40 & 4,27 & 4,34 & 4,43 & 4,14 & 3,79 & 8,15 & 8,14 & 7,97 \\
\hline $\mathrm{CaO}$ & 7,73 & 8,15 & 8,88 & 8,18 & 6,20 & 8,37 & 8,84 & 7,82 & 7,96 & 8,00 & 7,78 & 8,19 & 2,76 & 2,64 & 3,08 \\
\hline $\mathrm{Na} \mathrm{O}_{2}$ & 2,73 & 2,69 & 2,65 & 2,75 & 2,95 & 2,79 & 2,57 & 3,13 & 3,06 & 2,70 & 2,78 & 2,77 & 1,53 & 1,42 & 1,40 \\
\hline $\mathrm{K}_{2} \mathrm{O}$ & 1,59 & 1,34 & 1,12 & 1,46 & 2,33 & 1,47 & 1,24 & 1,51 & 1,45 & 1,48 & 1,62 & 1,48 & 0,52 & 0,46 & 0,69 \\
\hline $\mathrm{P}_{2} \mathrm{O}_{5}$ & 0,70 & 0,59 & 0,32 & 0,51 & 0,88 & 0,51 & 0,51 & 0,62 & 0,60 & 0,61 & 0,66 & 0,51 & 0,54 & 0,30 & 1,08 \\
\hline $\mathrm{LOI}$ & 1,05 & 1,35 & 0,27 & 0,71 & 1,30 & 0,50 & 0,05 & 0,42 & 0,76 & 0,78 & 0,78 & 0,45 & 100,75 & 100,74 & 100,86 \\
\hline $\mathrm{Total}$ & 100,87 & 100,63 & 100,99 & 100,59 & 100,90 & 100,84 & 100,67 & 100,78 & 100,83 & 100,40 & 100,85 & 100,47 & 56,95 & 53,05 & 61,26 \\
\hline $\mathrm{ID}$ & 58,55 & 55,96 & 59,17 & 56,44 & 62,95 & 56,69 & 52,28 & 55,89 & 55,41 & 55,28 & 56,30 & 56,40 & 56,95 & 53,05 & 61,26 \\
\hline$m g$ & 34,56 & 32,95 & 30,60 & 31,36 & 22,65 & 32,20 & 34,25 & 35,45 & 35,86 & 36,24 & 34,53 & 31,87 & 32,17 & 31,80 & 30,65 \\
\hline
\end{tabular}

\begin{tabular}{c|c|c|c|c|c|c|c|c|c|c|c|c|c|c|c}
\hline \multirow{2}{*}{ Amostra } & $\begin{array}{c}\text { AR- } \\
27 / 54\end{array}$ & $\begin{array}{c}\text { AR- } \\
28 / 56\end{array}$ & $\begin{array}{c}\text { AR- } \\
\text { 30/59 }\end{array}$ & $\begin{array}{c}\text { AR- } \\
30 / 60\end{array}$ & $\begin{array}{c}\text { AR- } \\
31 / 61\end{array}$ & $\begin{array}{c}\text { AR- } \\
32 / 62\end{array}$ & $\begin{array}{c}\text { AR- } \\
33 / 63\end{array}$ & $\begin{array}{c}\text { AR- } \\
34 / 64\end{array}$ & $\begin{array}{c}\text { AR- } \\
35 / 65\end{array}$ & $\begin{array}{c}\text { AR- } \\
35 / 66\end{array}$ & $\begin{array}{c}\text { AR- } \\
35 / 67\end{array}$ & $\begin{array}{c}\text { AR- } \\
35 / 68\end{array}$ & $\begin{array}{c}\text { AR- } \\
35 / 69\end{array}$ & $\begin{array}{c}\text { AR- } \\
35 / 70\end{array}$ & $\begin{array}{c}\text { AR- } \\
35 / 71\end{array}$ \\
\hline $\mathrm{SiO}_{2}$ & 51,67 & 54,76 & 49,27 & 49,88 & 51,64 & 52,30 & 51,93 & 51,29 & 49,72 & 49,40 & 49,79 & 49,72 & 49,49 & 49,70 & 50,64 \\
\hline $\mathrm{TiO}_{2}$ & 3,77 & 2,38 & 4,14 & 3,03 & 3,65 & 3,41 & 3,54 & 3,59 & 4,36 & 4,04 & 2,96 & 2,80 & 2,71 & 3,18 & 3,41 \\
\hline $\mathrm{Al}_{2} \mathrm{O}_{3}$ & 12,37 & 12,03 & 13,51 & 11,85 & 12,41 & 11,37 & 12,86 & 12,43 & 12,76 & 14,59 & 13,40 & 11,16 & 10,88 & 11,81 & 12,60 \\
\hline $\mathrm{FeO}_{\text {tot }}$ & 13,52 & 13,39 & 14,01 & 14,23 & 12,96 & 15,96 & 13,59 & 13,91 & 14,50 & 12,74 & 13,26 & 14,50 & 14,66 & 14,30 & 14,04 \\
\hline $\mathrm{MnO}$ & 0,20 & 0,22 & 0,19 & 0,21 & 0,22 & 0,22 & 0,22 & 0,19 & 0,20 & 0,17 & 0,20 & 0,22 & 0,22 & 0,22 & 0,21 \\
\hline $\mathrm{MgO}$ & 3,85 & 2,93 & 4,02 & 6,46 & 3,98 & 2,85 & 3,69 & 4,08 & 4,13 & 3,93 & 5,38 & 7,55 & 8,08 & 6,06 & 4,86 \\
\hline $\mathrm{CaO}$ & 7,71 & 6,66 & 8,87 & 8,87 & 7,75 & 6,73 & 7,68 & 7,50 & 8,70 & 9,18 & 9,81 & 9,21 & 9,26 & 8,82 & 8,56 \\
\hline $\mathrm{Na} \mathrm{O}_{2}$ & 2,73 & 2,77 & 2,82 & 2,42 & 2,68 & 2,70 & 2,89 & 3,06 & 2,64 & 2,95 & 2,59 & 2,27 & 2,21 & 2,38 & 2,65 \\
\hline $\mathrm{K}_{2} \mathrm{O}$ & 1,62 & 2,20 & 1,25 & 1,20 & 1,59 & 2,12 & 1,65 & 1,72 & 1,33 & 1,16 & 0,99 & 1,06 & 1,04 & 1,24 & 1,37 \\
\hline $\mathrm{P}_{2} \mathrm{O}_{5}$ & 0,69 & 0,89 & 0,42 & 0,41 & 0,69 & 0,70 & 0,64 & 0,66 & 0,45 & 0,35 & 0,35 & 0,37 & 0,36 & 0,43 & 0,49 \\
\hline $\mathrm{LOI}$ & 1,08 & 0,92 & 0,30 & 0,18 & 1,13 & 0,56 & 0,43 & 0,74 & 0,27 & 0,23 & 0,20 & 0,28 & 0,15 & 0,28 & 0,25 \\
\hline $\mathrm{Total}$ & 100,89 & 100,81 & 100,51 & 100,51 & 100,29 & 100,87 & 100,81 & 100,89 & 100,86 & 100,31 & 100,57 & 100,93 & 100,87 & 100,20 & 100,81 \\
\hline $\mathrm{ID}$ & 57,82 & 61,80 & 55,75 & 48,43 & 58,26 & 56,88 & 58,65 & 56,55 & 54,47 & 58,54 & 52,57 & 44,39 & 42,58 & 49,16 & 53,69 \\
\hline$m g$ & 33,46 & 27,84 & 33,59 & 44,45 & 35,13 & 23,93 & 32,36 & 34,11 & 33,44 & 35,23 & 41,70 & 47,87 & 49,29 & 42,74 & 37,87 \\
\hline
\end{tabular}

\begin{tabular}{c|c|c|c|c|c|c|c|c|c|c|c}
\hline Amostra & E-3/6 & E-15/34 & E-15/35 & E-15/36 & E-16/39 & E-18/41 & E-19/44 & E-19/45 & E-19/46 & E-21/54 & E-22/55 \\
\hline $\mathrm{SiO}_{2}$ & 50,51 & 58,17 & 51,08 & 50,08 & 51,12 & 53,34 & 51,11 & 51,12 & 50,70 & 50,04 & 48,46 \\
\hline $\mathrm{TiO}_{2}$ & 2,64 & 1,77 & 3,32 & 3,42 & 3,20 & 2,91 & 3,48 & 3,25 & 3,65 & 3,77 & 4,16 \\
\hline $\mathrm{Al}_{2} \mathrm{O}_{3}$ & 13,25 & 12,41 & 13,03 & 13,56 & 13,62 & 13,08 & 13,09 & 13,24 & 13,57 & 15,22 & 14,44 \\
\hline $\mathrm{FeO}_{\text {tot }}$ & 13,93 & 12,48 & 13,25 & 13,74 & 13,39 & 12,63 & 13,12 & 13,42 & 13,73 & 12,64 & 13,31 \\
\hline $\mathrm{MnO}$ & 0,08 & 0,15 & 0,14 & 0,16 & 0,14 & 0,10 & 0,18 & 0,13 & 0,18 & 0,13 & 0,12 \\
\hline $\mathrm{MgO}$ & 4,52 & 1,19 & 4,16 & 4,33 & 3,35 & 3,15 & 4,23 & 4,17 & 4,29 & 3,86 & 4,15 \\
\hline $\mathrm{CaO}$ & 7,97 & 5,18 & 8,13 & 7,69 & 8,02 & 6,96 & 7,81 & 7,56 & 7,14 & 8,15 & 9,01 \\
\hline $\mathrm{Na}_{2} \mathrm{O}$ & 3,03 & 3,36 & 2,89 & 2,80 & 3,05 & 3,13 & 3,01 & 3,10 & 2,93 & 3,02 & 3,04 \\
\hline $\mathrm{K}_{2} \mathrm{O}$ & 1,66 & 3,09 & 1,60 & 1,71 & 1,67 & 2,14 & 1,57 & 1,56 & 1,31 & 1,19 & 1,24 \\
\hline $\mathrm{P}_{2} \mathrm{O}_{5}$ & 0,69 & 0,66 & 0,76 & 0,82 & 0,78 & 1,00 & 0,77 & 0,80 & 0,81 & 0,41 & 0,43 \\
\hline $\mathrm{LOI}$ & 0,46 & 0,31 & 0,90 & 1,92 & 1,06 & 0,99 & 1,57 & 1,23 & 2,19 & 0,36 & 0,24 \\
\hline $\mathrm{Total}$ & 99,99 & 100,00 & 100,00 & 100,01 & 100,00 & 100,00 & 99,99 & 100,00 & 100,01 & 100,01 & 100,00 \\
\hline $\mathrm{ID}$ & 55,90 & 69,30 & 57,40 & 57,70 & 59,80 & 62,70 & 57,90 & 58,30 & 59,20 & 61,70 & 57,00 \\
\hline$m g$ & 36,40 & 14,50 & 35,60 & 35,70 & 30,60 & 30,60 & 36,20 & 35,40 & 35,60 & 35,00 & 35,50 \\
\hline $\mathrm{Cr}$ & 30 & 3 & 18 & 22 & 21 & 14 & 26 & 26 & 25 & 33 & 39 \\
\hline $\mathrm{Ni}$ & 10 & 1 & 4 & 3 & 1 & 2 & 6 & 2 & 4 & 21 & 13 \\
\hline $\mathrm{Cu}$ & 114 & 251 & 101 & 94 & 111 & 49 & 86 & 82 & 86 & 197 & 205 \\
\hline $\mathrm{Zn}$ & 97 & 114 & 90 & 85 & 87 & 102 & 77 & 84 & 88 & 78 & 77 \\
\hline $\mathrm{Ba}$ & 533 & 951 & 534 & 537 & 550 & 625 & 505 & 540 & 569 & 395 & 401 \\
\hline $\mathrm{Rb}$ & 35 & 70 & 26 & 35 & 29 & 45 & 36 & 37 & 26 & 30 & 21 \\
\hline $\mathrm{Sr}$ & 393 & 385 & 458 & 447 & 426 & 416 & 368 & 395 & 399 & 467 & 451 \\
\hline $\mathrm{Zr}$ & 201 & 380 & 212 & 219 & 202 & 254 & 202 & 209 & 215 & 162 & 157 \\
\hline $\mathrm{Y}$ & 40 & 66 & 34 & 37 & 36 & 53 & 35 & 40 & 41 & 27 & 26 \\
\hline $\mathrm{Nb}$ & 20 & 43 & 13 & 25 & 16 & 27 & 16 & 12 & 27 & 9 & 3 \\
\hline
\end{tabular}



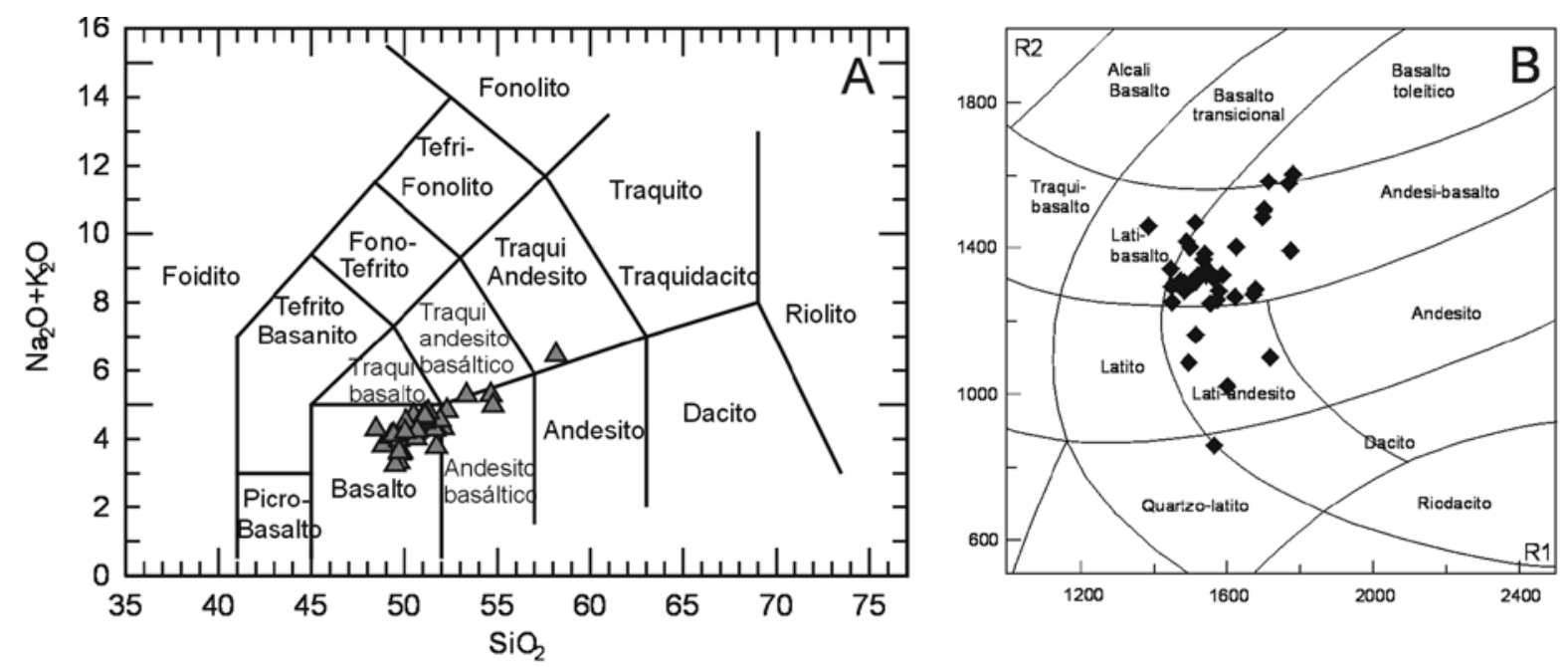

Figura 4 - Diagrama de classificação para as rochas da soleira de Reserva. (A) Diagrama TAS $\left(\left(\mathrm{Na}_{2} \mathrm{O}+\mathrm{K}_{2} \mathrm{O}\right)\right.$ vs. $\left.\mathrm{SiO}\right)$ de Le Maitre (1989) e (B) Diagrama R1 $(4 \mathrm{Si}-11(\mathrm{Na}+\mathrm{K})-2(\mathrm{Fe}+\mathrm{Ti})) v \mathrm{~s}$. R2 (6Ca $+2 \mathrm{Mg}+\mathrm{Al})$ de De La Roche et al. (1980).

em $\mathrm{SiO}_{2}, \mathrm{Na}_{2} \mathrm{O}, \mathrm{K}_{2} \mathrm{O}$ e $\mathrm{P}_{2} \mathrm{O}_{5}$ são atribuídos a processos de cristalização fracionada com contaminação, sendo o fracionamento dominado por fases minerais como piroxênio e plagioclásio.

Com relação aos elementos traço, a dispersão é moderada para Cr e Ni (Fig. 6), que definem trends negativos com a diminuição de $m g$, reforçando a proposta de fracionamento controlada por piroxênio. Entretanto, o Sr mostra dispersão com o decréscimo de $m g$, não definindo claramente o fracionamento de plagioclásio (Fig. 6). O diagrama de razão entre elementos traço, considerando $\mathrm{Zr} / \mathrm{Y}$ vs. Zr (Fig. 6) caracteriza razão constante entre $\mathrm{Zr}$ e Y, compatível com o modelo de cristalização fracionada. Com base no diagrama mulitelementar (Fig. 7) normalizado pelo manto primordial de Wood et al.(1979) observa-se que as rochas possuem assinaturas semelhantes, com anomalias negativas suaves em $\mathrm{Nb}$, que indicam processos de contaminação.

De acordo com os critérios de Piccirillo \& Melfi (1988) e de Peate (1997) os basaltos, microgabros e gabros da soleira de Reserva são classificados como de alto titânio (ATi), com concentrações variando entre 2,39 e $5,06 \%$. Apenas a amostra E-15/34 pertence ao grupo de baixo titânio (BTi), com teor igual a $1,77 \%$. As rochas analisadas classificam-se, segundo a proposta de Peate (1997) como magmas-tipo Pitanga e Paranapanema (Fig. 8).

MODELOS 2D Os modelos bidimensionais são produtos da interpolação de valores obtidos a partir de análises químicas, nos quais é possível observar a distribuição espacial dos parâmetros analisados. Os modelos foram construídos com o auxílio do software Surfer para as variáveis: $\mathrm{SiO}_{2}$, ID (índice de diferenciação de Thornton $\&$ Tuttle (1960), $m g \#(\mathrm{MgO} /(\mathrm{MgO}+\mathrm{FeO}))$ e $\mathrm{Ca} /(\mathrm{Ca}+\mathrm{Na})$ (Fig. 9). O ID, proposto por Thornton \& Tuttle (1960), utiliza minerais normativos (ID $=\mathrm{Q}+\mathrm{Or}+\mathrm{Ab}+\mathrm{Ne}+\mathrm{Ks}$ $+\mathrm{Lc})$ e sua concentração relaciona-se com o estágio de evolução da rocha. O limite do corpo intrusivo, utilizado nos modelos, foi traçado com o auxílio de fotografias aéreas e pela integração dos mapas geológicos propostos por Maniesi (1991) e Mineropar (2001).

A concentração de $\mathrm{SiO}_{2}$ varia entre 49,58 e $54,76 \%$, com as concentrações mais baixas distribuídas na faixa leste da soleira (Fig. 9A). O mapa de isovalores gerado para o ID é semelhante, onde se observa variação de 52 a $62 \%$ (Fig. 9B). Na faixa leste tem-se a porção menos diferenciada do corpo intrusivo, com ID inferior a 55. Nas porções sudoeste e norte são registradas as faixas mais diferenciadas da soleira, com ID superior a 59. Na faixa centro-sul observa-se pouca variação, com ID entre 55 a $57 \%$.

$\mathrm{O}$ mapa de isovalores da concentração $\mathrm{Ca} /$ $(\mathrm{Ca}+\mathrm{Na})$ é similar ao mapa de distribuição do ID, com maior concentração na faixa leste e porções de baixa concentração nas regiões norte e sudoeste da área (Fig. 9C).

$\mathrm{O} m g \#(\mathrm{MgO} /(\mathrm{MgO}+\mathrm{FeO}))$ varia de 27 a 46 , com predomínio na faixa entre 33 a 41 (Fig. 9D). As concentrações anômalas são observadas nas regiões nordeste e oeste da soleira. Na porção nordeste observam-se os valores mais elevados $(>42)$ e na região oeste, os mais baixos $(<30)$.

A concentração de álcalis $\left(\mathrm{Na}_{2} \mathrm{O}+\mathrm{K}_{2} \mathrm{O}\right)$ varia de 3,68 a 5,30 (Fig. 10A) e, à semelhança dos demais modelos construídos, as concentrações mais baixas ocorrem na faixa leste do corpo intrusivo. Com relação à concentração de $\mathrm{TiO}_{2}$, ocorre pouca variação (Fig. 10B). Entretanto, tem-se no centro do corpo uma faixa de direção NW com as concentrações mais elevadas registradas, superiores a $3,5 \%$. Nas regiões sudoeste e centro-leste do corpo ocorrem faixas com concentrações entre 2,4 a 3,0\%.

DISCUSSÕES E CONCLUSÕES A soleira de Reserva é formada por rochas de composição básica a intermediária, compostas por labradorita, augita, magnetita, ilmenita e quartzo, além de apatita, titanita e pirita como 

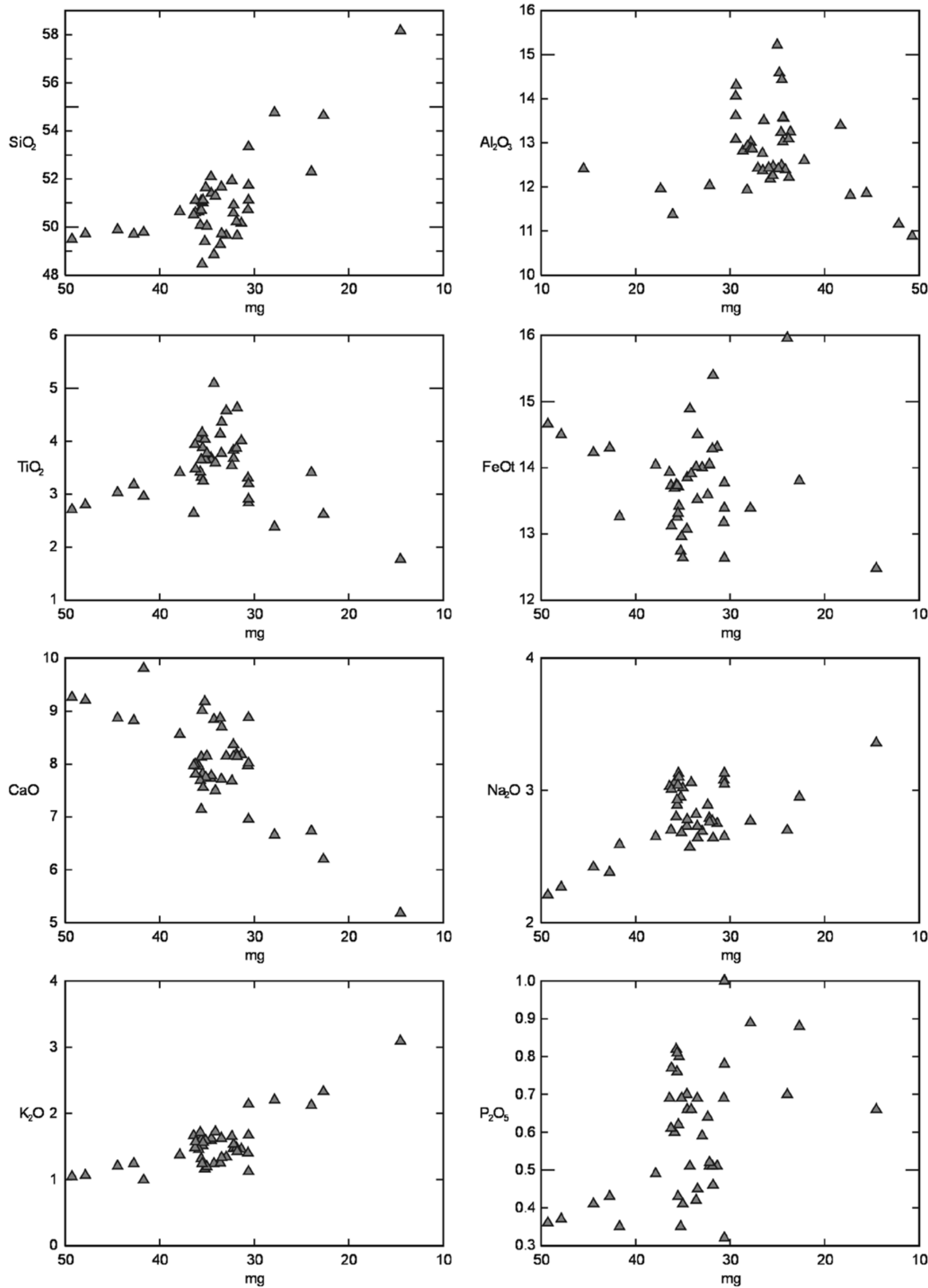

Figura 5 - Diagramas de variação para elementos maiores para as rochas da soleira de Reserva, tendo o $\mathrm{mg}(\mathrm{MgO} /(\mathrm{MgO}+\mathrm{feO}))$ como índice de diferenciação. 

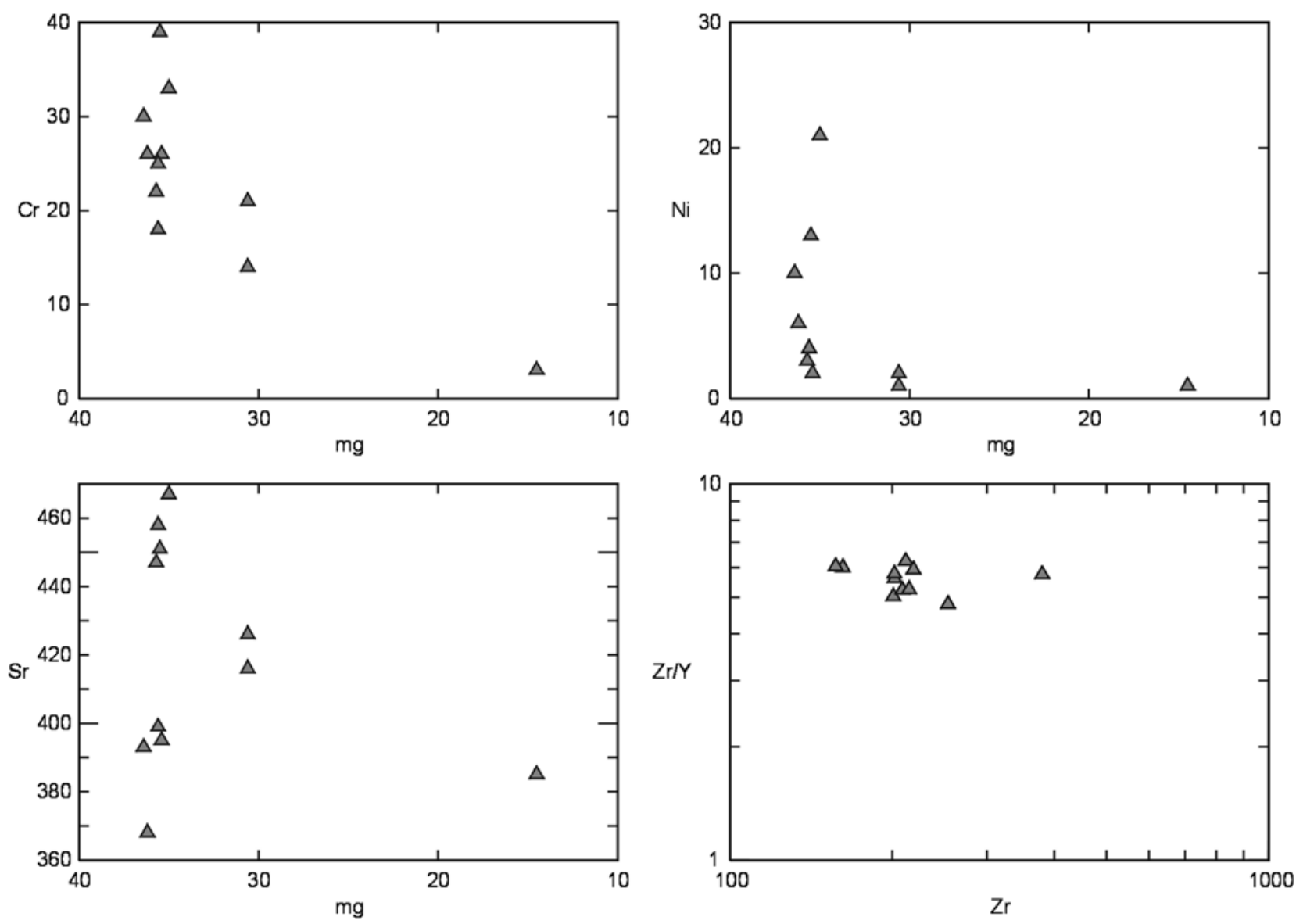

Figura 6 - Diagramas de variação para elementos traço (em ppm) para as rochas da soleira de Reserva, tendo o $\mathrm{mg}(\mathrm{MgO} /(\mathrm{MgO}+f e \mathrm{O})$ ) como índice de diferenciação (diagramas de a até c) e de razão $\mathrm{Zr} / Y$ vs. $\mathrm{Zr}(d)$.

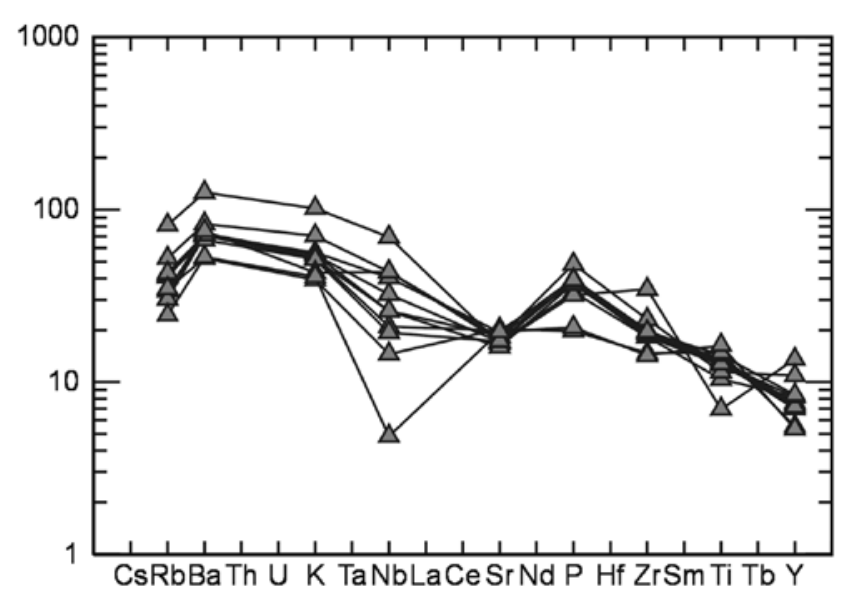

Figura 7 - Diagrama multielementar normalizado pelo manto primordial de Wood et al. (1979) para as rochas da soleira de Reserva.

acessórios, Ocorrem como minerais característicos do processo de alteração: argilominerais, micas e óxidos de ferro.

As rochas encaixantes, predominantemente folhelhos e siltitos, são marcadas por importantes varia-

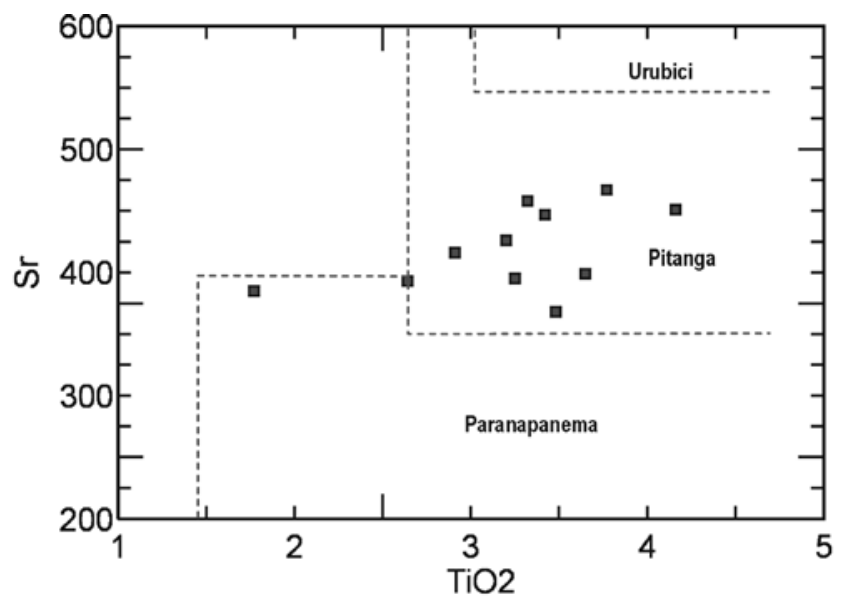

Figura 8 - Diagrama discriminante para as rochas da soleira de Reserva, segundo modelo proposto por Peate (1997).

ções composicionais e minerais no contato com o corpo intrusivo. Estas rochas se tornam gradativamente mais ricas em quartzo, além da perda progressiva da laminação e demais estruturas presentes, conforme aproximam- 


\section{A}

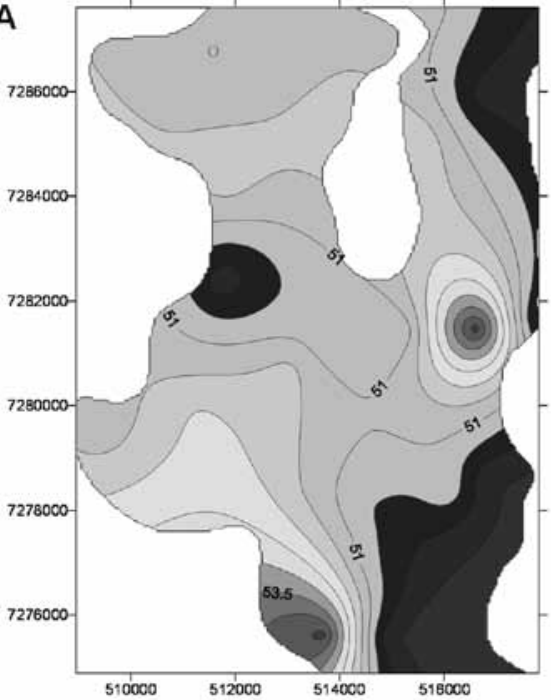

\section{C}

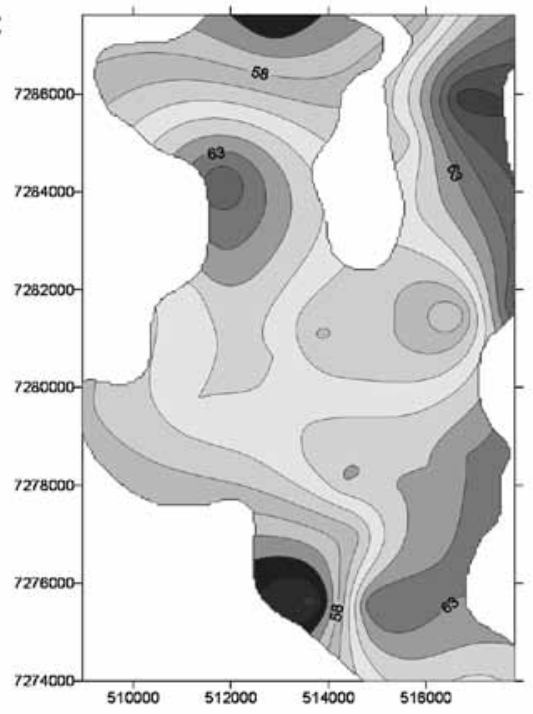

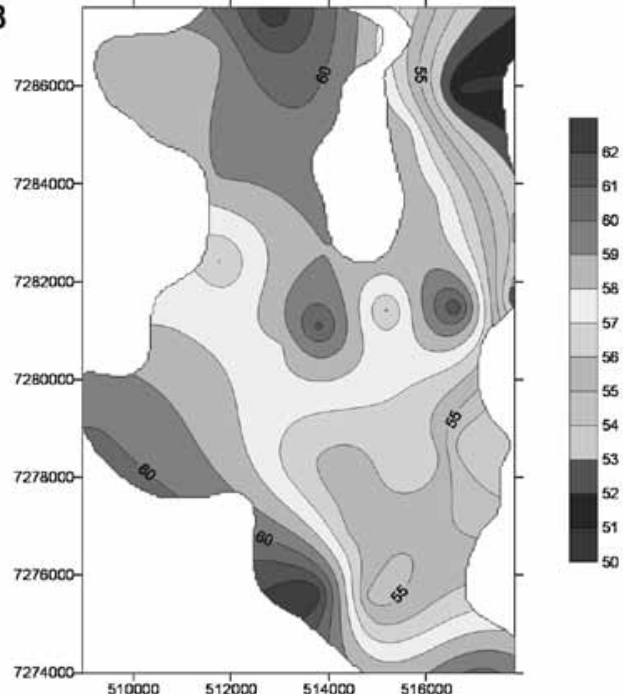

D

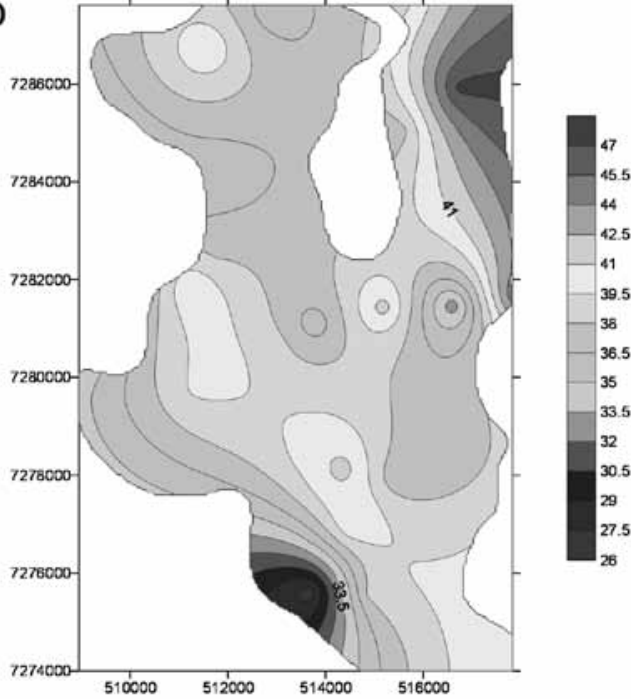

Figura 9 - Modelos de distribuição construídos para a soleira de Reserva. (A) Distribuição da variável $\mathrm{SiO}_{2}$, (B) Distribuição do índice de diferenciação (ID), (C) Distribuição da concentração $\mathrm{Ca} /(\mathrm{Ca}+\mathrm{Na})$ e (D) Distribuição do \#mg.
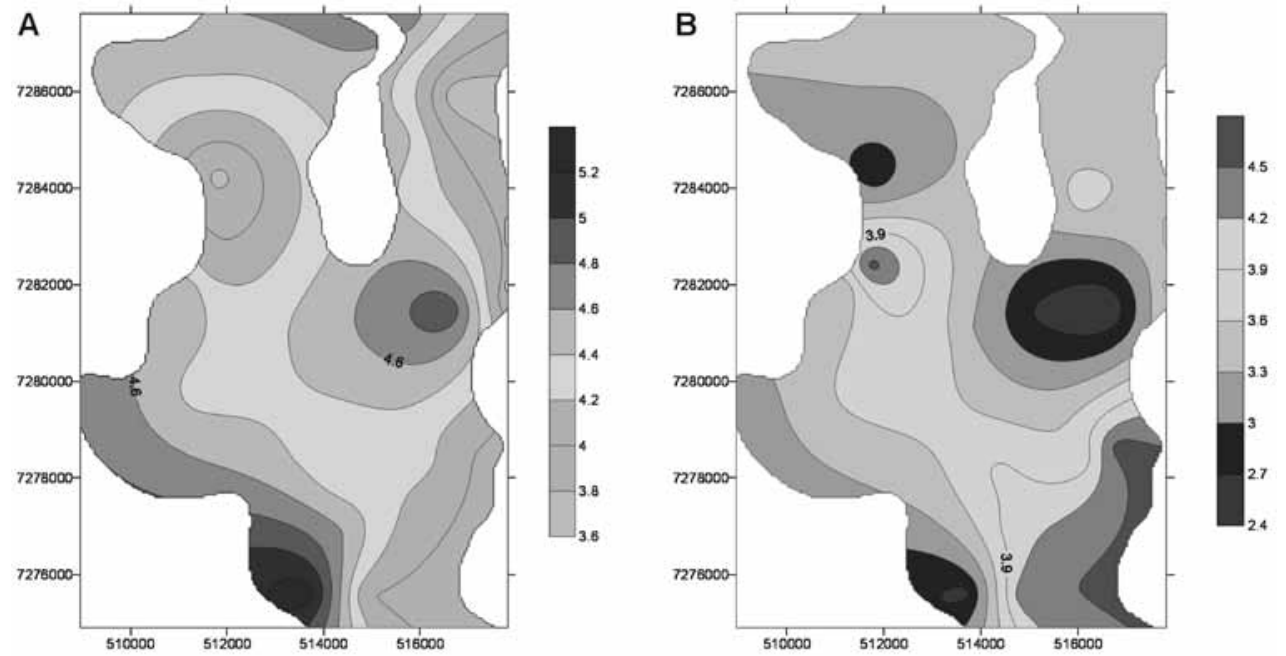

Figura 10 - Modelos de distribuição construídos para a soleira de Reserva. (A) Concentração $\left(\mathrm{Na}_{2} \mathrm{O}+\mathrm{K}_{2} \mathrm{O}\right)$ e (B) Concentração de $\mathrm{TiO}_{2}$. 
se do contato. Nas análises difratométricas identifica-se a presença de sanidina em todas as rochas analisadas, confirmada em análise petrográfica, que sugere que o metamorfismo de contato atingiu fácies sanidinito.

Quimicamente as rochas da soleira de Reserva são definidas como basaltos ou toleítos, basaltos andesíticos e latitos, predominantemente com alta concentração de $\mathrm{TiO}_{2}$. A cristalização fracionada com contaminação é definida como o processo magmático responsável para explicar a gênese e as variações composicionais das rochas analisadas.

Os modelos construídos para a soleira de Reserva demonstram a distribuição das variáveis geoquímicas, nos quais se constata uma equivalência direta entre os parâmetros analisados: as faixas menos diferenciadas correspondem àquelas de maior $m g \#$ e maior concentração de $\mathrm{Ca} /(\mathrm{Ca}+\mathrm{Na})$.
O modelo de distribuição do índice de diferenciação (ID) revela a presença de uma zona menos diferenciada na faixa leste do corpo, sugerindo que a evolução magmática se processou de leste para oeste. Esta observação é concordante com as variações na concentração de $\mathrm{MgO}$ registradas no corpo magmático, elevada (até $8,0 \%$ ) na faixa leste com decréscimo para oeste, onde as concentrações são inferiores a $2,0 \%$.

Agradecimentos Ao CNPq (Processo 460430/01-7), projeto "Modelo termal de formação das rochas ígneas da Formação Serra Geral (Bacia do Paraná) e sua influência nos sistemas petrolíferos Ponta Grossa-Itararé e Irati-Rio Bonito/Pirambóia". À Fundação Araucária (Protocolo 6085), projeto "Evolução térmica de sills da Formação Serra Geral e sua influência sobre as rochas sedimentares da Bacia do Paraná".

\section{Referências}

Bellieni G., Brotzu P., Comin-Chiaramonti P., Ernesto M., Melfi A.J., Pacca I.G., Piccirilo E.M., Stolfa D. 1983. Petrological and paleomagnetic data on the plateau basalts to rhyolite sequences of the Southern Paraná Basin (Brazil). Anais da Academia Brasileira de Ciências, 55:355-383.

Bellieni G., Brotzu P., Comin-Chiaramonti P., Ernesto M., Melfi A.J., Pacca I.G., Piccirillo E.M. 1984a. Flood basalt to rhyolite suites in the southern Paraná Plateau (Brazil): paleomagnetism, petrogenesis and geodynamic implications. Journal of Petrology, 25(3):579-618.

Bellieni G., Comin-Chiaramonti P., Marques L.S., Melfi A.J., Piccirillo E.M., Stolfa D. 1984b. Low-pressure evolution of basalts sills from bore-holes in the Paraná Basin, Brazil. Tschermaks Mineralogische und Petrographische Mitteilungen, 33:25-47.

Bellieni G., Comin-Chiaramonti P., Marques L.S., Melfi A.J., Nardy A.J.R., Papatrechas C., Piccirilo E.M., Roisenberg A. 1986. Petrogenetic aspects of acid and basaltic lavas from Paraná Basin (Brazil): geological, mineralogical and petrochemical relationships. Journal of Petrology, 27:915-944.

De La Roche H., Leterrier J., Grandclaude P., Marchal M. 1980. A Classification of Volcanic and Plutonic Rocks Using R1R2 - Diagram and Major Element Analyses Its Relationships with Current Nomenclature. Chemical Geology, 29:183-210.

Ernesto M., Raposo M.I.B., Marques L.S., Renne P.R., Diogo L.A., Min A. de. 1999. Paleomagnetism, geochemistry and 40Ar/39Ar dating of the north-eastern Paraná Magmatic Province: tectonic implications. Journal of Geodynamics, 28:321-340.

Ferreira F.J.F., Saad A.R., Santos M.V., Ferrari M.P., Viana R.B. 1982. Contribuição ao estudo do alinhamento estrutural de Guapiara. In: SBG, Simp. Reg. Geol., 3, Atas, p. 226-240.

Fodor R.V., Corwin C.T., Roisemberg A. 1985. Petrology of Serra Geral (Paraná) continental flood basalts, southern Brazil: crustal contamination, source material, and South
Atlantic magmatism. Contributions to Mineralogy and Petrology, 91:54-65.

Le Maitre R.W. 1989. A Classification of Igneous Rocks and Glossary of terms. Great Britain, Blackwell Sci. Pub., $193 \mathrm{p}$.

Maniesi V. 1991. Petrologia das soleiras de diabásio de Reserva e Salto do Itararé - PR. Dissertação de Mestrado, Instituto de Geociências, Universidade Estadual Paulista, 117 p.

Maniesi V., Oliveira M.A.F. 1997. Petrologia das soleiras de diabásio de Reserva e Salto Itararé, PR. Geochim. Brasil., 11:153-169.

Mantovani M.S.M., Cordani U.G., Roisenberg A. 1985. Geoquímica isotópica em vulcânicas ácidas da Bacia do Paraná e implicações genéticas associadas. Rev. Bras. Geoc., 15:61-65.

Marques L.S. \& Ernesto M. 2004. O magmatismo toleítico da Bacia do Paraná. In: Mantesso-Neto V., Bartorelli A., Carneiro C.D.R., Brito-Neves B.B. (eds.) Geologia do Continente Sul-Americano: evolução da obra de Fernando Flávio Marques de Almeida. São Paulo, Beca Produções Culturais, p. 245-263.

Milani E.J. \& Thomaz Filho A. 2000. Sedimentary Basins of South América. In: Cordani U.G., Milani E.J., Thomaz Filho A., Campos D.A. (eds.) Tectonic Evolution of South America. In-Fólio Produção Editorial, p. 389-449.

MINERAIS DO PARANÁ S/A (MINEROPAR). 2001. Atlas Geológico do Estado do Paraná. Curitiba, MINEROPAR, CD-Rom.

Peate D.W. 1997. The Paraná-Etendeka province. In: Mahoney J.J. \& Coffin M.F. Large Igneous Provinces: Continental, Oceanic and Planetary Flood Volcanism. Washington, DC: American Geophysical Union, p. 217245.

Peate D.W., Hawkesworth C.J., Mantovani M.S.M., Shukowsky W. 1990. Mantle plumes and flood-basat stratigraphy in the Paraná, South America. Geology, 18:1223-1226.

Peate D.W., Mantovani M.S.M., Hawkesworth C.J. 1996. 
Geochemical stratigraphy of the Paraná continental flood basalts: borehole evidence. Rev. Bras. Geoc., 2:212-221.

Petersohn E. 2006. Evolução térmica de sills encaixados nas formações Irati e Ponta Grossa (Bacia do Paraná) no Estado do Paraná - contribuição para o entendimento da evolução dos sistemas petrolíferos Irati - Rio Bonito/ Pirambóia e Ponta Grossa - Itararé. Dissertação de Mestrado, Departamento de Geologia, Universidade Federal do Paraná, 120 p.

Piccirillo E.M., Raposo M.I.B., Melfi A., CominChiaramonti P., Bellieni G., Cordani U.G., Kawashita K. 1987. Bimodal fissural volcanic suites from the Paraná Basim (Brazil): K-Ar age, Sr-isotopes and geochemistry. Geochim. Brasil., 1:53-69.

Piccirillo E.M., Comin-Chiaramonti P., Melfi A., Stolfa D., Bellieni G., Marques L.S., Giaretta A., Nardy A.J. R., Pinese J.P.P., Raposo M.I.B., Roisemberg A. 1988. Petrochemistry of continental flood basalts rhyolite suites and related intrusives from the Paraná Basin (Brazil). In: Piccirillo E.M. \& Melfi A.J. (eds.) The Mesozoic flood volcanism of the Paraná Basin petrogenetic and geophysical aspects. São Paulo: USP, p. 107-156.

Piccirillo E.M. \& Melfi A.J. 1988. The Mesozoic flood volcanism of the Paraná Basin - petrogenetic and geophysical aspects. São Paulo: USP, 600 p.

Thornton C.P. \& Tuttle O.F. 1960. Chemistry of igneous rocks: differentiation index. Amer. Journ. Science, 258:664-684.

Vasconcellos E.M.G., Peterson E., Barbosa M.A.D., Vanzela G.A., Mancini F., Pinese J.P.P., Cândido A.G. 2003. Estudo petrográfico e geoquímico de sills encaixados nas rochas sedimentares da Formação Irati no Estado do PR. In: SBGq, Congres. Bras. Geoq., 9, Anais, p. 1-4.

Vasconcellos E.M.G., Vanzela G.A., Petersohn E. 2005. Quimismo mineral de sills associados à Província Magmática do Paraná, no Estado do Paraná. In: SBG, Congres. Bras. Geoq., 10, Anais, p. 1-3.

Wood D.A., Tarney J., Varet J., Saunders A.D., Bougault H., Joron J.L., Treuil M., Cann J.R. 1979. Geochemistry of basalts drilled in the North Atlantic by IPOD Leg. 49: implications for mantle heterogeneity. Earth Planet. Sci. Lett., 42:77-97.

Manuscrito ID 10755

Submetido em 24 de fevereiro de 2008 Aceito em 11 de dezembro de 2009 